\title{
Fibrinolytic and inflammatory processes in pleural effusions
}

\author{
F. Philip-Joët*, M-C. Alessi**, C. Philip-Joët**, M. Aillaud**, J-R. Barriere*, \\ A. Arnaud*, I. Juhan-Vague**
}

Fibrinolytic and inflammatory processes in pleural effusions. F. Philip-Joët, M-C. Alessi, C. Philip-Joët, M-F. Aillaud, J-R. Barriere, A. Arnaud, I. Juhan-Vague. (CERS Journals Ltd 1995.

ABSTRACT: This study was designed to evaluate major fibrinolytic parameters in relation to parameters of inflammation associated with different kinds of pleural effusion.

Sixty patients with pleural effusion were studied. The underlying aetiology was empyema in 10 cases, tuberculosis in 9, cancer in 31, cardiac failure in 7, and undetermined in 3. Plasminogen, plasminogen activator inhibitor 1 (PAI-1) and 2 (PAI2), tissue type plasminogen activator (t-PA), urokinase (u-PA) and D-dimers (D-D) were quantified in plasma samples and pleural effusion specimens. These data were then correlated with inflammatory or infectious parameters, i.e. fibrinogen, von Willebrand factor (vWF), erythrocyte sedimentation rate (ESR), protein concentration, and white blood cell count.

D-D levels were higher in pleural fluid than in plasma. D-D levels were not correlated with either plasminogen activator or plasminogen activator inhibitor levels, suggesting the presence of other fibrinolytic pathways. PAI levels (PAI activity, PAI-1 antigenicity, PAI-2 antigenicity) and vWF levels were significantly higher in patients with tuberculosis and empyema than in patients with cancer or cardiac failure. Regression analysis between inflammatory and fibrinolytic parameters showed that pleural PAI levels were significantly correlated with pleural neutrophil count, vWF levels, and plasma fibrinogen levels. D-D levels were correlated with blood ESR. No significant difference in pleural t-PA, u-PA and D-D levels was observed between aetiologies. The highest pleural t-PA and u-PA values were noted in patients with cancer, especially lymphoma. Plasma t-PA levels were higher in patients with pleural effusion secondary to congestive heart failure, but this difference did not reach statistical significance.

In conclusion, pleural PAI levels are related to polymorphonuclear count and vWF levels, i.e. to inflammatory processes. Elevated levels of plasminogen activators suggest a possible role in some malignant pleural diseases.

Eur Respir J., 1995, 8, 1352-1356.
*Service de Pneumologie-Allergologie, CHU Nord, Marseille, France. **Laboratoire d'Hématologie, CJF INSERM 93/12 Faculté de Médecine, Marseille, France.

Correspondence: F. Philip-Joet

Service de Pneumologie-Allergologie

CHU Nord

13915 Marseille Cedex 20

France

Keywords: Cancer

cardiac failure

empyema

fibrinolysis

pleural effusion

tuberculosis

Received: July 41994

Accepted after revision April 61995
Activity of several haemostatic factors has been detected in pleural fluids [1]. In patients with exudative processes, an increase in procoagulant activity, due mainly to tissue factor, has been observed [2]. The fibrinolytic system (fig. 1), which is responsible for lysis of fibrin to balance fibrin deposition, is regulated by precise interplay between activators and inhibitors [3].

In patients with pleural effusions, high intrapleural levels both of tissue type plasminogen activator (t-PA), urokinase (u-PA) and their inhibitors (PAI) have been found. Intrapleural hypofibrinolysis, due mainly to excessive concentration of inhibitors, has been postulated in these patients [2]. Conversely, D dimer (D-D) level, a marker of solid phase fibrin dissolution was found to be high in patients with malignant effusion, suggesting local fibrinolysis activation [4].

Plasma fibrinolytic activity has been shown to be modulated by inflammation in vivo [5]. In agreement with this fact, D-D levels decreased in the pleural space after quinacrine instillation used to cause inflammation and fibrin deposition in treatment of malignant effusions by pleurodesis [4]. These findings suggest a relationship between intrapleural fibrinolysis and inflammatory parameters.

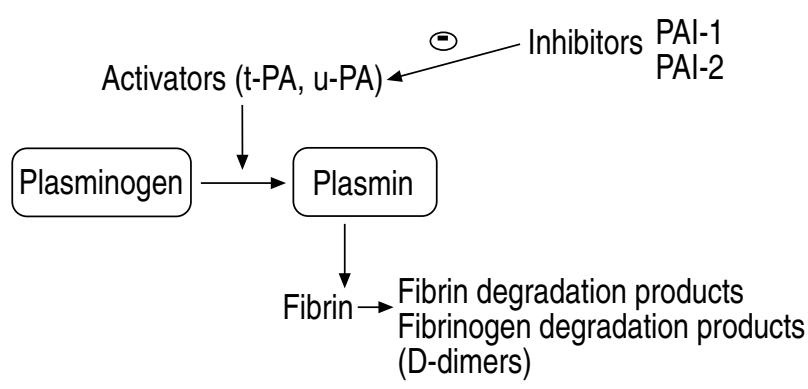

Fig. 1. - Components of the fibrinolytic system and their effects upon fibrin. PAI-1 and PAI-2: plasminogen activator inhibitor 1 and 2; t-Pa: tissue type plasminogen activator; u-Pa: urokinase. 
Von Willebrand factor (vWF) is secreted constitutively by endothelial cells, and plays a key role in platelet adhesion, thrombus formation [6]. vWF is likely to be released at the site of infection and inflammation through the action of histamine, complement components, cytokines or oxygen radicals [7].

This study was designed to evaluate the relationship between plasminogen activators, plasminogen activator inhibitors, D-D, vWF and the inflammatory status in human pleural fluid and plasma in patients with various types of pleural disease.

\section{Patients and methods}

\section{Patients}

This study included 60 consecutive patients hospitalized for pleural effusion. There were 36 males and 24 females, with a mean age of 62 yrs (range 32-79 yrs).

\section{Study design}

Diagnosis was based on clinical data, biopsy, cytology and usual biochemical tests. Empyema was defined as the presence of purulent material in the pleural space, with or without bacteria on Gram stains and cultures. Tuberculosis was diagnosed by pleural biopsy showing specific lesions and/or detection of tuberculosis bacillus by direct microscopic examination or culture. Cancer was documented in all cases by percutaneous pleural biopsy. Pleural effusion was attributed to heart failure if clinical, electrocardiographic (ECG), radiographic and echographic evidence of congestive heart failure was found, and if the fluid was a transudate with a protein level less than $30 \mathrm{~g} \cdot \mathrm{L}^{-1}$ [8].

\section{Methods}

Pleural effusion specimens from the first needle puncture were tested. For haemostasis testing, samples were collected in vacutainer tubes on $3.8 \%$ citrate. Cells were separated by centrifugation $(2,000 \times \mathrm{g}$ for $30 \mathrm{~min})$ and the supernatant was frozen at $-30^{\circ} \mathrm{C}$. Blood samples were collected on citrate between 8.00 a.m. and 10.00 a.m. on the same day as effusion specimens.

Plasminogen was evaluated using a chromogenic substrate (Stachrom, PLG, Stago Asnières, France). PAI activity was determined using a functional assay (spectrolyse/fibrin, Biopool, Umea, Sweden). Plasminogen activator inhibitor-1 (PAI-1) and 2 (PAI-2), tissue type plasminogen activator (t-PA), and urokinase (u-PA) antigens $(\mathrm{Ag})$ were determined by an enzyme-linked immunosorbent assay (ELISA) using commercially available kits (Biopool). D-D and t-PA/PAI-1 complexes were also measured by ELISA (Stago) [9]. Clottable fibrinogen was measured by the method of Clauss and von Willebrand factor (vWf) by ELISA (Stago). Laboratory assessment also included erythrocyte sedimentation rate
(ESR), pleural protein concentration (nephelometry, Behringwerk AG, Marburg, Germany) and white cell count (Technicon H6000). These parameters were measured in duplicate in blood and/or pleural samples.

Analysis

Results are expressed as means \pm standard error. Blood and effusion parameters were compared using the paired Wilcoxon t-test. Intergroup variations for variables were first determined by Kruskal Wallis one-way analysis of variance (ANOVA). Specific comparison of variables between two groups was made using the Mann Whitney test. Correlations were obtained by the Spearman's test. A p-value less than 0.05 was considered to show a significant difference

\section{Results}

The aetiology of pleural effusion was empyema in 10 cases, tuberculosis in 9, cancer in 31 , cardiac failure in 7 , and undetermined in 3.

\section{Comparison of pleural and plasma specimens (table 1)}

PAI (PAI activity(act), PAI-1 Ag, PAI-2 Ag) and D$D$ levels were higher in pleural fluid than in plasma. The pleural fluid/plasma PAI ratio was higher than the pleural fluid/plasma protein ratio. Plasminogen, fibrinogen and $\mathrm{vWF}$ levels were higher in plasma than in pleural fluid.

\section{Pleural levels}

Pleural fluid protein concentrations were significantly lower in patients with congestive heart failure (fig. 2).

PAI levels (PAI act, PAI-1 Ag, PAI-2 Ag) and vWF levels were higher in patients with tuberculosis and empyema than in those with cancer or cardiac failure (fig. 3).

Table 1. - Comparison between pleural and plasma levels in all patients

\begin{tabular}{|c|c|c|c|}
\hline Parameter & Pleural fluid & Plasma & p-value \\
\hline PAI-1 Ag $\mathrm{ng} \cdot \mathrm{mL}^{-1}$ & $490 \pm 81$ & $32 \pm 2$ & 0.0001 \\
\hline PAI- 1 act $\mathrm{u} \cdot \mathrm{mL}^{-1}$ & $22.6 \pm 3$ & $7.3 \pm 0.9$ & 0.0001 \\
\hline PAI-2 Ag $\mathrm{ng} \cdot \mathrm{mL}^{-1}$ & $53.9 \pm 7$ & $0 *$ & ND \\
\hline $\mathrm{t}-\mathrm{PA} \mathrm{Ag} \quad \mathrm{ng} \cdot \mathrm{mL}^{-1}$ & $13.6 \pm 1.6$ & $11.3 \pm 1$ & NS \\
\hline $\mathrm{u}-\mathrm{PA}-1 \mathrm{Ag} \quad \mathrm{ng} \cdot \mathrm{mL}^{-1}$ & $5.8 \pm 1.7$ & $0 *$ & ND \\
\hline $\mathrm{D}-\mathrm{D} \mu \mathrm{g} \cdot \mathrm{mL}^{-1}$ & $499 \pm 43$ & $1.15 \pm 0.06$ & 0.0001 \\
\hline Plasminogen $\mathrm{u} \cdot \mathrm{mL}^{-1}$ & $0.28 \pm 0.03$ & $1.13 \pm 0.04$ & 0.0001 \\
\hline Fibrinogen $\mathrm{g} \cdot \mathrm{L}^{-1}$ & $1.07 \pm 0.32$ & $5.7 \pm 0.35$ & 0.0001 \\
\hline $\mathrm{vWF} \quad \mathrm{u} \cdot \mathrm{mL}^{-1}$ & $0.66 \pm 0.07$ & $2.9 \pm 0.2$ & 0.0001 \\
\hline Protein $\mathrm{g} \cdot \mathrm{L}^{-1}$ & $39.7 \pm 2$ & $66.2 \pm 1$ & 0.0001 \\
\hline
\end{tabular}

Data are presented as mean \pm SEM. *: less than the detection threshold. PAI-1 and PAI-2: plasminogen activator inhibitor 1 and 2; Ag: antigen; act: activity; t-PA: tissue type plasminogen activator; u-PA: urokinase; D-D: D-dimer; vWF; von Willebrand factor; ND: not done; ns: not significant. 


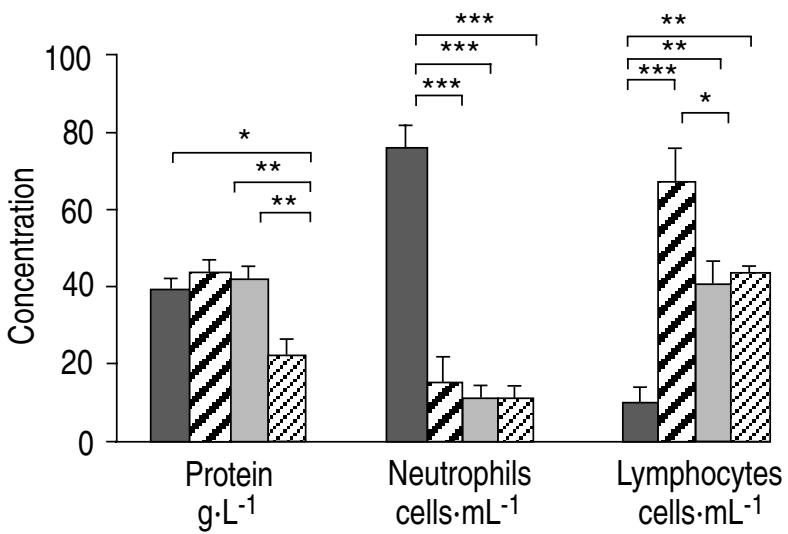

Fig. 2. - Pleural protein level, polymorphonuclear and lymphocyte counts in relation to aetiology (mean value \pm SEM). ${ }^{*}: \mathrm{p}<0.05 ;{ }^{* *}: \mathrm{p}<0.01$; ${ }^{* * *}$ : $\mathrm{p}<0.005$, Mann Whitney test. $\square$ : empyema; $\square$ : tuberculosis; $\square$ : cancer; $\mathbb{Z}$ : cardiac failure.

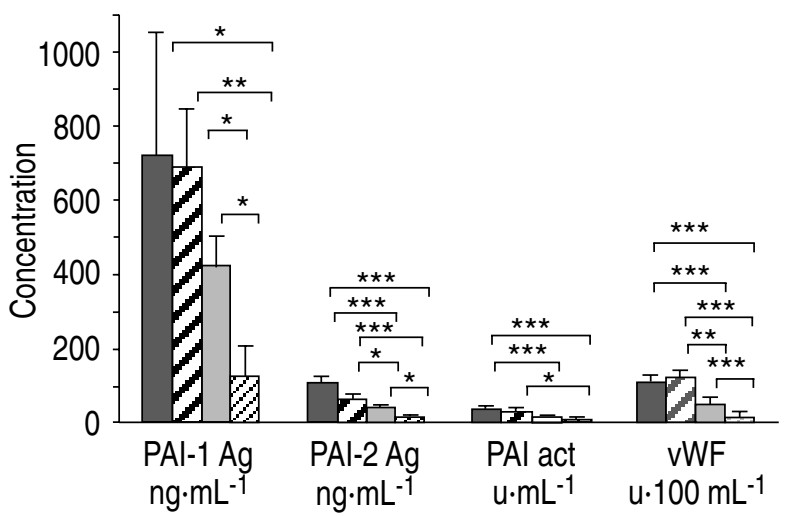

Fig. 3. - Pleural PAIs and von Willebrand factor levels in function of aetiology (mean value \pm SEM). ${ }^{*}: \mathrm{p}<0.05 ;{ }^{* *}: \mathrm{p}<0.01 ;{ }^{* *}: \mathrm{p}<0.005$, Mann Whitney test. Ag: antigen; act: activity; vWF: von Willebrand factor. For further abbreviations see legend to figure 1. $\square$ : empyema; $\angle$ : tuberculosis; $\square$ : cancer; $\mathbb{Z}$ : cardiac failure.

Plasminogen, t-PA Ag, u-PA Ag and fibrinogen levels were not statistically different according to aetiology. However, t-PA Ag and u-PA Ag were high in cancer patients. It is noteworthy that among cancer patients the highest t-PA Ag and u-PA Ag levels were observed in the six patients with lymphoma (t-PA Ag: $32 \pm 7$ vs $14 \pm 2$ $\mathrm{ng} \cdot \mathrm{mL}^{-1}$ in other cancer patients $(\mathrm{p}=0.02)$; $\mathrm{u}-\mathrm{PA} \mathrm{Ag}$ : $29 \pm 18$ vs $4 \pm 1 \mathrm{ng} \cdot \mathrm{mL}^{-1}$ in other cancer patients $(\mathrm{p}=0.06)$ ). Table 1 gives mean values for all patients.
D-D levels in patients with heart failure $(334 \pm 117$ $\left.\mu \mathrm{g} \cdot \mathrm{mL}^{-1}\right)$ tended to be lower than in patients with tuberculosis $\left(632 \pm 44 \mu \mathrm{g} \cdot \mathrm{mL}^{-1}\right)$, empyema $\left(425 \pm 98 \mu \mathrm{g} \cdot \mathrm{mL}^{-1}\right)$ or cancer $\left(516 \pm 60 \mu \mathrm{g} \cdot \mathrm{mL}^{-1}\right)$. These differences were not significant.

\section{Plasma levels (table 2)}

u-PA or PAI-2 could not be detected in plasma of any patients (lower limit of detection $1 \mu \mathrm{g} \cdot \mathrm{mL}^{-1}$ ).

The highest plasma t-PA Ag levels were observed in patients with cardiac failure. This finding may be related to the presence of inactive PAI-1/t-PA complexes (4 \pm 1.5 vs $1 \pm 0.5 \mathrm{ng} \cdot \mathrm{mL}^{-1}$ in healthy subjects). In empyema, plasma PAI-1 Ag levels were elevated and there was no increase in t-PA Ag or PAI act levels. This finding suggests that PAI-1 was inactive, and thus unable to complex with t-PA. Indeed, the levels of PAI-1/t-PA complexes were lower in patients with empyema than in those with cardiac failure $\left(2.1+0.5 \mathrm{ng} \cdot \mathrm{mL}^{-1}\right)$.

Plasma fibrinogen levels were higher in exudates than in transudates, but this difference was not statistically significant.

\section{Correlations between fibrinolytic parameters in pleural fluid}

D-D was not significantly correlated with plasminogen activator or PAI levels, suggesting that the balance between plasminogen activators and specific inhibitors did not strictly determine fibrinolysis in pleural fluid. PAI act was correlated with PAI-1 Ag $(r=0.64 ; p<0.001)$ and PAI-2 Ag ( $\mathrm{r}=0.59 ; \mathrm{p}<0.001)$. PAI-1 Ag was correlated with PAI-2 $\mathrm{Ag}(\mathrm{r}=0.34 ; \mathrm{p}<0.01)$.

\section{Correlations between pleural fibrinolytic parameters and markers of inflammation}

Some fibrinolytic parameters were correlated with inflammatory or infectious markers. Pleural PAI levels were correlated with pleural neutrophil count: PAI act $(\mathrm{r}=0.33 ; \mathrm{p}<0.01)$, PAI-1 Ag $(\mathrm{r}=0.32 ; \mathrm{p}=0.01)$, PAI-2 Ag $(\mathrm{r}=0.39 ; \mathrm{p}<0.01)$ and also with pleural vWF levels: PAI act

Table 2. - Plasma levels according to underlying aetiology

\begin{tabular}{|c|c|c|c|c|c|}
\hline Parameter & Empyema & Tuberculosis & Cancer & Cardiac failure & p-value* \\
\hline Plasminogen $\mathrm{u} \cdot \mathrm{mL}^{-1}$ & $1.05 \pm 0.13$ & $1.22 \pm 0.11$ & $1.13 \pm 0.04$ & $1.2 \pm 0.04$ & 0.61 \\
\hline PAI-1 Ag $\mathrm{ng} \cdot \mathrm{mL}^{-1}$ & $40.7 \pm 7.1$ & $24.2 \pm 3.8$ & $29.8 \pm 4.0$ & $43.7 \pm 9.2$ & 0.08 \\
\hline PAI act $\mathrm{u} \cdot \mathrm{mL}^{-1}$ & $6.0 \pm 1.5$ & $11.3 \pm 3.6$ & $5.8 \pm 0.8$ & $9.9 \pm 3.8$ & 0.28 \\
\hline $\mathrm{t}-\mathrm{PA} \mathrm{Ag} \quad \mathrm{ng} \cdot \mathrm{mL}^{-1}$ & $10.9 \pm 1.4$ & $10.8 \pm 2$ & $9.5 \pm 1.0$ & $20.6 \pm 5.1$ & 0.06 \\
\hline $\mathrm{D}-\mathrm{D} \quad \mu \mathrm{g} \cdot \mathrm{mL}^{-1}$ & $1.20 \pm 0.11$ & $1.15 \pm 0.08$ & $1.13 \pm 0.09$ & $1.20 \pm 0.11$ & 0.7 \\
\hline Fibrinogen $\mathrm{g} \cdot \mathrm{L}^{-1}$ & $8.0 \pm 1$ & $5.9 \pm 0.7$ & $4.9 \pm 0.4 * *$ & $5.5 \pm 1.1$ & 0.04 \\
\hline $\mathrm{vWF} \quad \mathrm{u} \cdot \mathrm{mL}^{-1}$ & $2.8 \pm 3$ & $2.9 \pm 1.7$ & $3.0 \pm 0.2$ & $2.4 \pm 0.2$ & 0.7 \\
\hline Protein $\mathrm{g} \cdot \mathrm{L}^{-1}$ & $65 \pm 3$ & $66 \pm 4$ & $65 \pm 2$ & $62 \pm 4$ & 0.8 \\
\hline ESR $\mathrm{mm}$ & $78 \pm 8$ & $50 \pm 8$ & $49 \pm 6$ & $56 \pm 8$ & 0.06 \\
\hline
\end{tabular}

Data are presented as mean \pm SEM. PAI-2 Ag and u-PA Ag were below the threshold of detection. *: Kruskall Wallis, comparison between the groups; **: Mann Whitney; empyema $v s$ cancer, $\mathrm{p}=0.06$. ESR: erythrocyte sedimentation rate. For further abbreviations see legend to table 1 . 
$(\mathrm{r}=0.58 ; \mathrm{p}<0.001)$, PAI-1 Ag $(\mathrm{r}=0.61 ; \mathrm{p}<0.001)$ and PAI$2 \mathrm{Ag}(\mathrm{r}=0.38 ; \mathrm{p}<0.01)$. Pleural PAI-act and PAI-2 Ag were positively correlated with plasma fibrinogen $(\mathrm{r}=0.38$; $\mathrm{p}<0.01$ and $\mathrm{r}=0.41 ; \mathrm{p}<0.01$, respectively).

Pleural u-PA Ag was correlated with pleural protein $(\mathrm{r}=0.35 ; \mathrm{p}<0.01)$. Pleural D-D were positively correlated with blood ESR $(\mathrm{r}=0.44 ; \mathrm{p}<0.01)$ and pleural protein $(r=0.48 ; p<0.01)$. Pleural t-PA Ag was not correlated with any of the parameters tested.

\section{Discussion}

In vivo fibrin formation is controlled by fibrinolysis.

Previous reports using the fibrin plate assay [2] have shown fibrinolytic activity in the pleural effusions of all patients except those with transudates. The fibrin plate assay is a method that evaluates the balance between plasminogen activators and inhibitors on standardized fibrin plate in vitro. The D-D assay is a method that evaluates the effect of the activator/inhibitor balance on fibrin in vivo. Our results showed high pleural D-D levels in all patients with pleural effusion, suggesting either strong fibrinolytic activity or poor clearance of locally produced D-D. These data and the lack of correlation between $\mathrm{D}-\mathrm{D}$ and plasminogen activators and inhibitors suggest the existence of another fibrinolysis activation pathway in pleural fluid.

Several findings indicate that fibrinolytic activity in plasma is related to inflammation. Numerous studies have correlated decreased plasma fibrinolytic activity with elevated PAI-1 in patients with septicaemia and during postoperative recovery [10]. Similarly, a positive correlation has been reported between plasma PAI-1 levels and inflammatory protein [5]. The fibrinolytic process has also been implicated in cancer invasion by converting plasminogen to active plasmin, which causes degradation of matrix components [11, 12].

As previously noted [2], pleural PAI-1 levels were significantly higher in exudates than in transudates. High PAI-1 levels in pleural fluid could result either from systemic production with diffusion in the pleura due to increased microvascular permeability, or from local production as suggested by the high pleural/plasma ratio. The increase of PAI-1 levels was correlated with polymorphonuclear count, plasma fibrinogen level and pleural vWF levels. These observations favour the hypothesis that PAI-1 production is induced by an inflammatory process. The high correlation observed between PAI-1 and $\mathrm{vWF}$ levels suggests a common pathway of regulation during pleural inflammation. One implication of this correlation is a possible role of the endothelium in pleural inflammation during infection or cancer. Mesothelial or endothelial cells are able to increase their PAI-1 production in response to different cytokines (tumour necrosis factor- $\alpha$ (TNF $\alpha)$, interleukin-1(IL-1) [13] and growth factors [14]. This ability could account for the increased pleural levels observed during infection or cancer.

PAI-2 levels were also higher in pleural exudates. PAI2 is known to be produced both by placental tissue and macrophages [15], and has been observed in peritoneal fluid [16]. As recently shown by SAXNE et al. [17], polymorphonuclear cells might be involved in PAI-2 synthesis and could explain the slightly higher PAI-2 levels observed in patients with empyema as compared to patients with tuberculosis. The role of polymorphonuclear cells is further supported by the correlation observed between PAI-2 levels and pleural neutrophils. In patients with cardiac failure, the mechanism underlying the accumulation of pleural fluid involves increased hydrostatic pressure and, consequently, PAI-2 and PAI-1 levels remain low.

Plasminogen activator levels were not significantly different according to aetiology. However, they did tend to be increased in malignant effusions. Like IDELL et al. [2], we found high pleural t-PA Ag levels in adenocarcinoma but we observed the highest levels in patients with lymphoma. The pleural fluid/plasma t-PA Ag ratio was high in cancer and low in chronic heart failure. The difference could be explained by a decrease in venous return and hepatoclearance in association with low cardiac output [18]. The fact that plasma PAI-1 Ag levels also appeared to be high even when PAI-1 act levels were low suggests the presence of an excess of inactive PAI-1/t-PA complexes in the plasma of these patients.

In conclusion, regulation of the balance between plasminogen activators and inhibitors was different according to the aetiology of pleural effusion. Pleural PAI levels were greatly enhanced in exudates due to inflammatory or infectious process. In contrast, plasminogen activator levels were increased in malignant effusions, particularly those due to lymphoma. We observed a strong increase in pleural D-D levels in all patients with pleural effusion. This finding did not appear to be correlated with pleural fluid plasminogen activators and inhibitors. Pleural PAI levels are related to pleural polymorphonuclear count, vWF levels and plasma fibrinogen levels, i.e. to inflammation. Elevated levels of plasminogen activators may play a role in some malignant pleural diseases.

Acknowledgements: The authors thank J. Ansaldi and A. Vampiro for excellent technical assistance, and A. Corsini for his help in translation.

\section{References}

1. Glauser FL, Otis PT, Levine RI, Smith WR. In vitro pleural fluid clottability and fibrinogen content. Chest 1975; 68: 205-208.

2. Idell S, Girard W, Koenig KB, McLarty J, Fair DS. Abnormalities of pathways of fibrin turnover in the human pleural space. Am Rev Respir Dis 1991; 144: 187-194.

3. Bachmann F. Fibrinolysis. Thrombosis and Haemostasis. XIth congress of the International Society on Thrombosis and Haemostasis. In: Verstraete M, Vermylen J, Lijnen R, Arnout J, eds. Leuven, Leuven University Press, 1987; pp. 227-265.

4. Agrenius V, Chmielewska J, Widstöm O, Blombäck M. Pleural fibrinolytic activity is decreased in inflammation as demonstrated in quinacrine pleurodesis treatment of malignant pleural effusion. Am Rev Respir Dis 1989; 140: $1381-1385$. 
5. Juhan-Vague I, Alessi MC, Joly P, et al. Plasma plasminogen activator inhibitor-1 in angina pectoris: influence of plasma insulin and acute-phase response. Arteriosclerosis 1989; 9: 362-367.

6. Ruggeri ZM, Ware J. The structure and function of von Willebrand factor. Thromb Haemost 1992; 67: 594-599.

7. Wagner DD. The Weibel-Palade body: the storage granule for von Willebrand factor and P-selectin. Thromb Haemost 1993; 70: 105-110.

8. Widstrom O, Nilsson BS. Acute and chronic infections. In: Chrétien J, Bignon J, Hirsch A, eds. The pleura in health and disease. New York, M. Dekker Publishing, 1985; 23: 445-460.

9. Eisenberg PR, Jaffe AS, Stump DC, Collen DC, Bovill EG. Validity of enzyme-linked immunosorbent assays of cross-linked fibrin degradation products as a measure of clot lysis. Circulation 1990; 82: 1159-1168.

10. Kruithof EKO. Plasminogen activator inhibitor type 1: biochemical, biological and clinical aspects. Fibrinolysis 1988; 2: 59-70.

11. Dano K, Andreasen PA, Grondahl Hansen J, Kristensen P, Nielsen LS, Skriver L. Plasminogen activators, tissue degradation and cancer. Cancer Res 1985; 44: 139-226.

12. Saksela O, Rifkin BD. Cell associated plasminogen activation: regulation and physiological functions. Annu Rev Cell Biol 1988; 4: 93-126.
13. Van Hinsbergh VWM, Kooistra T, van den Berg EA, Princen HMG, Fiers W, Emeis JJ. Tumor necrosis factor increases the production of plasminogen activator inhibitor in human endothelial cells in vitro and rats in vivo. Blood 1988; 72: 1467-1473.

14. Pepper MS, Belin D, Montesano R, Orci L, Vassali JD. Transforming growth factor-beta ${ }_{1}$ modulates basic fibroblast growth factor-induced proteolytic and angiogenic properties of endothelial cells in vitro. J Cell Biol 1990; 111: 743-755.

15. Sprengers ED, Kluft C. Plasminogen activator inhibitors. Blood 1987; 69: 381-387.

16. Whavell SA, Vipond MN, Scott-Coombes DM, Thompson JN. Plasminogen activator inhibitor-2 reduces peritoneal fibrinolytic activity in inflammation. Br J Surg 1993; 80: 107-109.

17. Saxne T, Lecander I, Geborek P. Plasminogen activators and plasminogen activator inhibitors in synovial fluid: difference between inflammatory joint disorders and osteoarthritis. J Rheumatol 1993; 20: 91-96.

18. Huber K, Beckmann R, Probst P, Rauscha F, Kaindl F, Binder BR. Influence of cardiac output on peak t-PA plasma levels in patients receiving thrombolytic therapy with recombinant tissue type plasminogen activator: correlation with patency rate. Thromb Haemost 1993; 69: 45-49. 